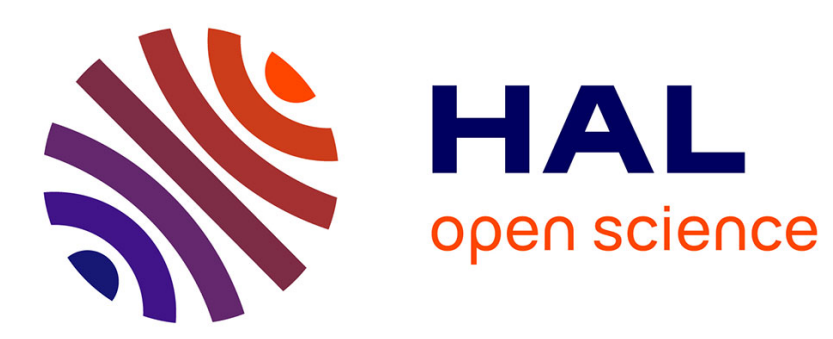

\title{
A diagnosis-based approach for tire-road forces and maximum friction estimation
}

Jorge Villagra, Brigitte d'Andréa-Novel, Michel Fliess, Hugues Mounier

\section{To cite this version:}

Jorge Villagra, Brigitte d'Andréa-Novel, Michel Fliess, Hugues Mounier. A diagnosis-based approach for tire-road forces and maximum friction estimation. Control Engineering Practice, 2011, 19 (2), pp.174-184. 10.1016/j.conengprac.2010.11.005 . inria-00533586

\section{HAL Id: inria-00533586 \\ https://hal.inria.fr/inria-00533586}

Submitted on 7 Nov 2010

HAL is a multi-disciplinary open access archive for the deposit and dissemination of scientific research documents, whether they are published or not. The documents may come from teaching and research institutions in France or abroad, or from public or private research centers.
L'archive ouverte pluridisciplinaire HAL, est destinée au dépôt et à la diffusion de documents scientifiques de niveau recherche, publiés ou non, émanant des établissements d'enseignement et de recherche français ou étrangers, des laboratoires publics ou privés. 


\title{
A diagnosis-based approach for tire-road forces and maximum friction estimation
}

\author{
Jorge VILLAGRA ${ }^{\mathrm{a},}$, Brigitte d'ANDRÉA-NOVEL ${ }^{\mathrm{b}}$, , Michel FLIESS ${ }^{\mathrm{c}}$, Hugues \\ MOUNIER $^{\mathrm{d}}$ \\ ${ }^{a}$ Centro de Automática y Robótica, UPM-CSIC, 28500 Arganda del Rey (Madrid), Spain \\ ${ }^{b}$ Mines ParisTech, CAOR-Centre de Robotique, Mathématiques et Systèmes, 60 Bd St Michel \\ 75272 Paris Cedex 06, France \\ ${ }^{c}$ INRIA-ALIEN \& LIX (CNRS, UMR 7161) École polytechnique, 91128 Palaiseau, France \\ ${ }^{d}$ L2S (CNRS, UMR 8506), Supélec \& Université Paris-Sud, 3 rue Joliot-Curie, 91192 \\ Gif-sur-Yvette, France
}

\begin{abstract}
A new approach to estimate vehicle tire forces and road maximum adherence is presented. Contrarily to most of previous works on this subject, it is not an asymptotic observer based estimation, but a combination of elementary diagnosis tools and new algebraic techniques for filtering and estimating derivatives of noisy signals. In a first step, instantaneous friction and lateral forces will be computed within this framework. Then, extended braking stiffness concept is exploited to detect which braking efforts allow to distinguish a road type from another. A weighted Dugoff model is used during these "distinguishable" intervals to estimate the maximum friction coefficient. Very promising results have been obtained in noisy simulations and real experimentations for most of driving situations.
\end{abstract}

Key words: Active safety, Friction estimation, Automotive vehicles, Nonlinear

Email addresses: jorge.villagra@car.upm-csic.es (Jorge VILLAGRA), brigitte. dandrea-novel @mines-paristech. fr (Brigitte d'ANDRÉA-NOVEL), Michel.Fliess@polytechnique .edu (Michel FLIESS),

Hugues. Mounieralss.supelec.fr(Hugues MOUNIER) 
estimation, Derivatives of noisy signals.

\section{Introduction}

Automobile manufacturers have dedicated enormous efforts on developing intelligent systems for road vehicles in the last two decades. Thus, many systems have been deeply studied in order to increase safety and improve handling characteristics. Considerable work has been carried out on collision avoidance, collision warning, adaptive cruise control and automated lane-keeping systems. In addition, more and more cars are nowadays equipped with anti-lock brake system (ABS), traction control system (TCS) (also called ASR for anti-slip regulation) or many variants of the Electronic Stability Program (ESP).

As such systems become more advanced, they increasingly depend on accurate information about the state of the vehicle and its surroundings. Much of this information can be obtained by direct measurement, but the appropriate sensors may be unreliable, inaccurate, or prohibitively expensive. Indeed, these enhancements must be a priori related to an optimal usability of the existing hardware. ${ }^{1}$

Since all the above-mentioned control systems have to be 'road-adaptive' (i.e. the control algorithms can be modified to take into account the external driving condition of the vehicles), the knowledge of the vehicle state and tire forces turns out to be essential.

Furthermore, most of these systems are based on an efficient transmission of the forces from vehicle wheels to the road surface. Tire efforts that act during severe maneuvers are nonlinear and may easily cause instability. Besides, they

\footnotetext{
${ }^{1}$ Let us recall that only measurements from encoders, longitudinal and lateral accelerometers, and yaw rate gyroscope are usually available trough the CAN bus.
} 
depend on uncontrollable external factors, such as tire pressure and wear, vehicle loads, and, particularly, on tire-road interface properties.

Friction is the major mechanism for generating those forces on the vehicle. Hence, knowing the longitudinal and vertical tire-road efforts $\left(F_{x}, F_{z}\right)$, and therefore the maximum friction coefficient

$$
\mu_{x_{\max }}=\left.\frac{F_{x}}{F_{z}}\right|_{\max }
$$

is crucial, since the maximum braking performance is related to the maximum tire-road friction coefficient.

The goal of this work is to find real-time estimators of the vehicle tire forces and of the maximum tire-road friction coefficient with actual on-board hardware and sensors.

\subsection{State of the art}

The lack of commercially available transducers to measure road friction directly led to several kinds of tire-road friction estimation approaches have been proposed in the literature. Some cause-based techniques try to detect physical factors that affect the friction coefficient. Although experimental results sometimes show a high accuracy, these methods usually present one of these two fundamental drawbacks:

- They require specific sensors, such as lubricant, optical or shaft torque sensors, that are not usually included in a production car.

- They rely on complex tire models, which are always highly road-dependent. 
Static and dynamic tire force models have been developed for accurate simulation of advanced control systems (see, e.g., [5], [20], [30], [34] or [43]). Extensive testing is required however to determine the parameters of those analytic models. It is therefore extremely difficult to determine all those parameters in real-time for every potential tire, tire pressure, and wear state.

Nevertheless, many authors have tried to use robust analytic techniques to determine tire-road friction coefficient from tire force models. Thus, simplified models have been coupled with vehicle dynamics to produce different observation and filtering techniques: [25] employed a neural-network based identification; [10] used fuzzy logic techniques; [24], [28], [35] and [42] developed different leastsquared methods; [6], [16], [22], [27], [31] or [33] use several kinds of nonlinear asymptotic observers. Most of them try to obtain reliable tire effort estimates and, thereafter, the maximum tire friction value by fitting different types of polynomial functions.

Unfortunately, these approaches are either based on too restrictive hypotheses, for instance only longitudinal dynamics situations, or on non-standard measurements, like wheel torque. Moreover, most of them concentrate their efforts on precise tire forces estimation, but they do not go into maximum friction estimation in depth.

A different research line is focused on the effects generated by friction. The effects are shown in the tire as, for instance, an acoustic characteristic (cf. [4]), tire/tread deformation (cf. [8]) and wheel slip. Concerning the latter, [17] used the idea that a larger slip at a given tire force would indicate a more slippery road. Observing the correlation between slip and friction coefficient can provide $\mu_{\max }$ information. However, under low slip situations, it becomes really hard to 
distinguish between different road types from noisy measurements.

Two possible solutions can be applied to that problem: using a GPS as proposed by [18], which is not always available on a production car, or exploit what [28] and [37] call the extended braking stiffness (XBS). It can be defined as the slope of friction coefficient against slip velocity at the operational point. Its value is related to the friction coefficient because the maximum braking force can be obtained when XBS is equal to zero ( $\operatorname{see}^{2}$ Fig. 1).

Note that snow, and specially ice, exhibit a very short transition between linear and nonlinear zones. Therefore, the XBS based algorithm presented here will correctly behaves for wet and dry roads, but it will probably not be so efficient for ice conditions.

Since in the $\tau-\mu_{x}$ linear zone $\mu_{x_{\max }}$ is hardly identifiable, the present work relies on the accurate estimation of XBS when non-linear behavior takes shape (soon enough to avoid wheel saturation). Diagnosis tools will be used, combined with new algebraic filtering techniques and a weighted Dugoff model, to consecutively estimate slip ratios, longitudinal and lateral tire forces, and longitudinal and lateral maximum friction coefficients.

In addition to accuracy and reliability, production cost is an important matter in vehicle serial production. In that sense, the proposed estimation approach is especially efficient in terms of computational cost, at least when compared with most of the above mentioned observer-based approaches. Furthermore, only standard and low cost sensors will be required in order to implement the proposed

\footnotetext{
${ }^{2}$ Friction coefficient is plotted in terms of slip ratios for several tire-road interfaces following pseudo-static Pacejka [29] tire model. These characteristic curves have been obtained by fitting real data of a half range commercial car under very different conditions.
} 


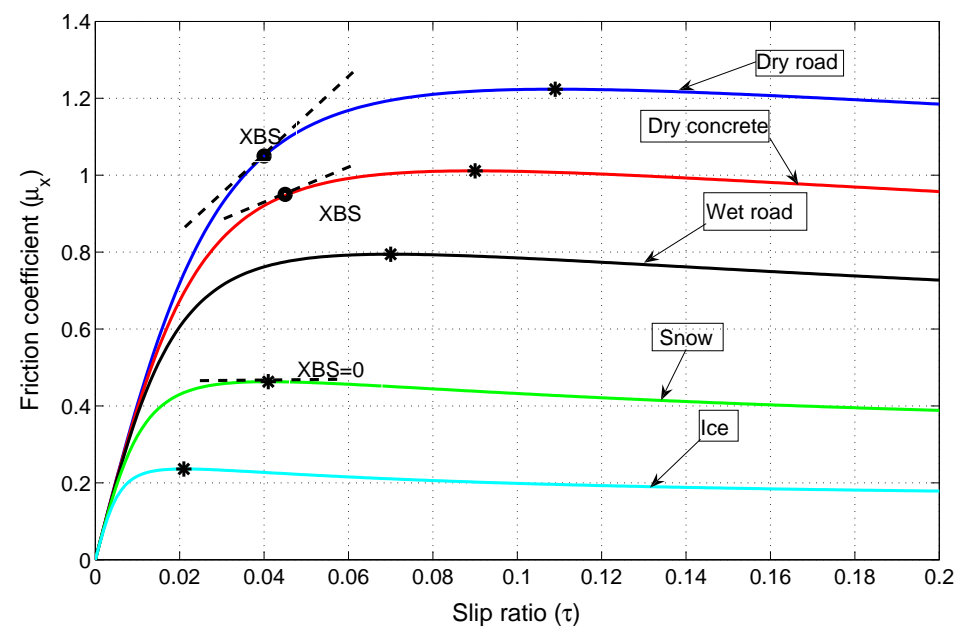

Figure 1: Adhesion coefficient characteristic curve for several tire-road interfaces (top); XBS definition (bottom)

algorithm.

\subsection{Outline of the article $e^{3}$}

Section 2 is devoted to present the proposed global estimation scheme. New algebraic techniques for derivative estimation will be combined with elementary diagnosis tools in order to design new estimators (an overview of this framework will be presented in Section 2.1). The first example of that approach will be introduced in Section 3, where a pitch diagnosis-based estimator will allow to obtain a good estimate of the instantaneous friction coefficient. A simple but efficient lateral effort estimator will be also presented in this Section. Once these variables are estimated, the maximum friction coefficient may be known. Section 4 will deal with the problem of distinguishing different road surfaces enough ahead of

\footnotetext{
${ }^{3}$ A preliminary version was presented in [41].
} 


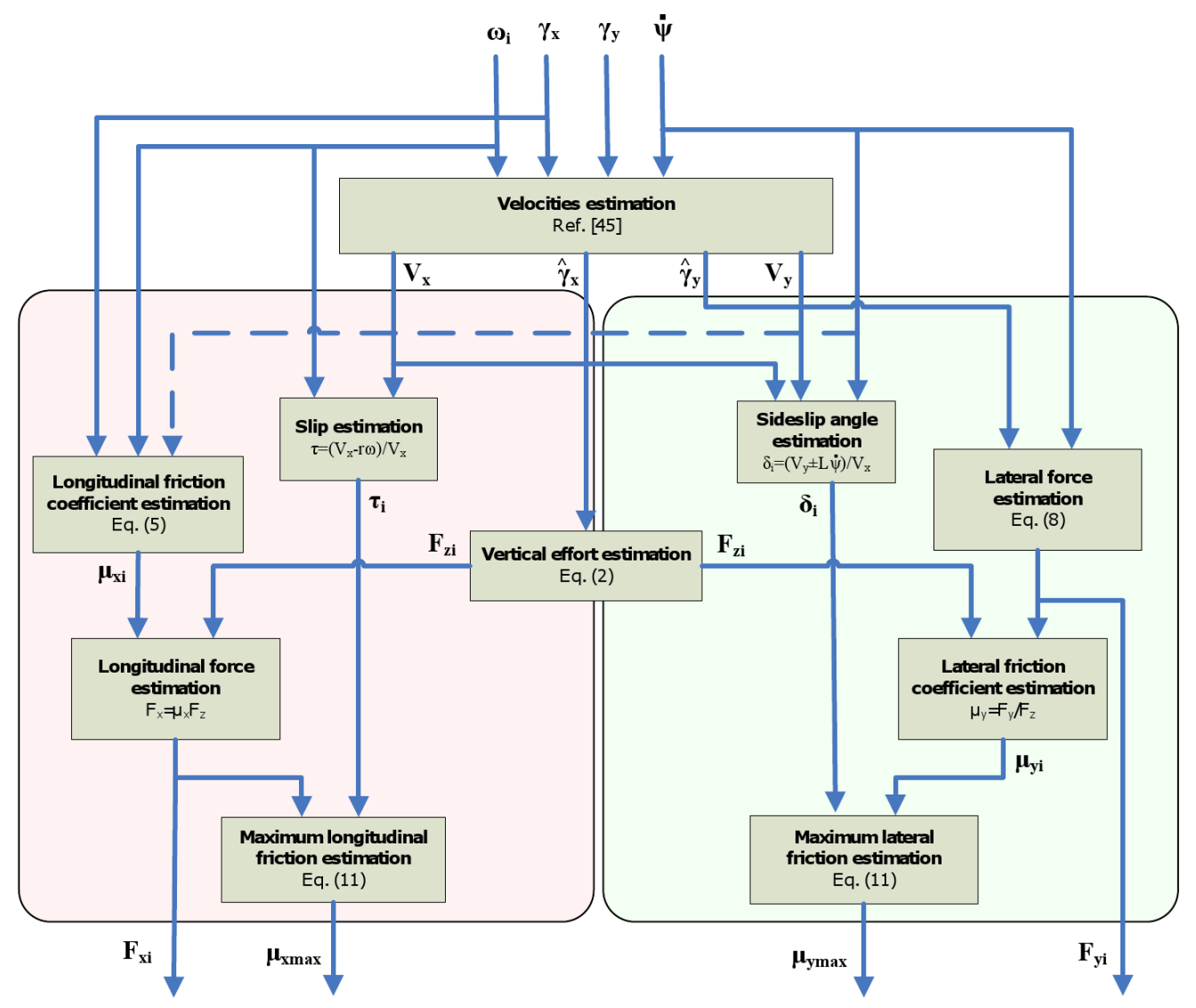

Figure 2: Global vehicle dynamics estimation scheme 
time to avoid undesirable control actions. In Section 5 two different scenarios will be used to test the quality of the estimator on multi-adherence roads. Preliminary experimental results are presented in Section 6, where the algorithm will be tested with experimental recorded data from a real vehicle. Finally, some concluding remarks will be given in Section 7.

\section{Global estimation scheme}

The vehicle is equipped with several proprioceptive sensors (typical measurements are longitudinal and lateral accelerations, yaw rate, odometries and steering angle) and, eventually, with exteroceptive sensors (radar, laser, camera, ... ). All this information can be used to estimate, among others, the maximum longitudinal and lateral friction coefficients $\left(\mu_{x}\right.$ and $\left.\mu_{y}\right)$. The way it is obtained is depicted in Fig. 2. This work needs only 7 measurable signals to provide a maximum friction estimator: longitudinal and lateral accelerations (the former from airbag systems, the latter from ESP systems), wheel angular velocities and yaw rate (from ESP systems as well).

Longitudinal and lateral velocities $\left(V_{x}, V_{y}\right)$ are the first step to obtain any information about the tire-road interaction. The work [40] solves this problem without any vehicle nor road parameter. Two natural byproducts of this estimation algorithm are the slip ratio $\tau$ and the sideslip angle $\delta_{i}$, where the subscript $i=f, r$ denotes front and rear, respectively. Efficient estimation algorithms for vertical $F_{z}$ effort have already been developed in the past (see, e.g., [15]), so that this work will take advantage of them. A new simple and reliable way to estimate the longitudinal friction estimation $\mu_{x}$ and the lateral efforts $F_{y_{i}}$ will be presented in the first part of this article (see Section 3). The friction coefficient will be used, on the 
one hand to obtain the longitudinal tire-road efforts $F_{x_{i}}$, and on the other hand, together with the estimated slip ratios, the maximum longitudinal coefficient $\mu_{x_{\max }}$. Finally, a similar procedure will allow to estimate the maximum lateral friction coefficient $\mu_{y_{\max }}$ from lateral efforts and sideslip angles.

It is important to remark that $\mu_{x_{\max }}$ and $\mu_{y_{\max }}$ will be obtained using XBS concept under the assumption of pure longitudinal or pure lateral movements, respectively. In this respect, figures 7 and 6 graphically shows that the proposed longitudinal and lateral effort estimator perform in a satisfactory way when combined longitudinal-lateral maneuvers take place. However, a deep study on the influence of forces correlation in the estimation accuracy seem necessary for real implementation.

\subsection{Diagnosis-based estimation within an algebraic framework}

In diagnosis terminology, a residual is defined as the amount by which an observation differs from its expected value. It is often used in fault tolerant control to detect a failure (for instance, in sensors or actuators) and act consequently.

This idea will be used in an estimation context to detect an abnormal behavior with respect to an ideal prediction model. In other words, the estimated variable can be considered as the sum of an ideal term and a "disturbing" one. ${ }^{4}$

The condition to decide wether the ideal term is valid or not to estimate the unknown variable is usually hard to obtain. Indeed, highly corrupted signals provided by the vehicle sensors and fixed integration step determined by signals sampling rate impose a signal pre-treatment. In addition, robust and real-time efficient

\footnotetext{
${ }^{4}$ Those disturbing terms are nothing else than "poorly known" effects. See [11] for the control of poorly known systems.
} 


\begin{tabular}{ll}
\hline Variable name & Symbol \\
\hline Longitudinal velocity & $V_{x}$ \\
Lateral velocity & $V_{y}$ \\
Vertical velocity & $V_{z}$ \\
Yaw rate and acceleration & $\dot{\psi}, \ddot{\psi}$ \\
Pitch angle and rate & $\phi, \dot{\phi}$ \\
Wheel speed & $\omega$ \\
Sideslip angle & $\delta$ \\
Slip ratio & $\tau$ \\
Longitudinal acceleration & $\gamma_{x}$ \\
Lateral acceleration & $\gamma_{y}$ \\
Longitudinal force & $F_{x}$ \\
Lateral force & $F_{y}$ \\
Vertical force & $F_{z}$ \\
Inst. and max. friction coefficient & $\mu_{x}, \mu_{x_{\max }}$ \\
Lateral friction coefficient & $\mu_{y}, \mu_{y_{\max }}$ \\
Wheelbase & $L$ \\
Height of the center of gravity & $h$ \\
Vehicle mass & $K_{\phi}$ \\
Yaw inertia moment & \multicolumn{1}{l}{} \\
Longitudinal stiffness coefficient & \\
\hline Pitch stiffness coefficient & \\
\hline
\end{tabular}

Table 1: List of variables 
numerical differentiators are also needed to render this approach feasible.

An algebraic framework [26] is proposed to deal with filtering and estimating derivatives of noisy signals. It is important to point out that these fast filters and estimators are not of asymptotic nature, and do not require any statistical knowledge of the corrupting noises (see [14] for a short discussion on the connections with some aspects of digital signal processing). This original way of treating conventional problems ought to be viewed as a change of paradigm in many control and signal processing aspects (see [13] and the references therein).

\section{Tire-road friction estimation}

It has already been pointed out that longitudinal tire-road friction coefficient has a major importance on any braking action. However, when braking is combined with a turning maneuver, lateral tire effort estimation become also critical for two different reasons:

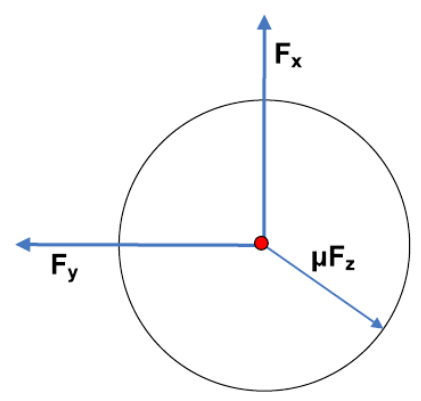

Figure 3: Kamm friction circles $\left(\sqrt{F_{x}^{2}+F_{y}^{2}} \leqslant \mu F z\right)$

- Steering angle or differential braking applied to the vehicle to correct the trajectory (or the dynamical behavior of the vehicle) depends explicitly on those efforts. 
- Longitudinal tire forces are coupled with lateral ones, so that the most braking force a wheel must transfer, the less lateral guiding force it is able to provide, and viceversa. This inter-dependency is characterized in Kamm effort circles (see figure 3 or [21] for more details).

As a consequence of all this, both lateral and longitudinal efforts need to be estimated. The next Sections will present an approach to separately solve both problems within the framework introduced in Section 2.1.

\subsection{Longitudinal friction estimation}

As explained in Section 2, besides the longitudinal and lateral velocities knowledge (see [40]), one of the first steps in the global estimation scheme is to obtain an estimator for vertical loads in the tire-road interface. They may be pretty well approached by considering pitch rate and vertical velocity steady-state equations (cf. [15]):

$$
\left\{\begin{aligned}
F_{z_{r}} L_{r}-F_{z_{f}} L_{f} & =M \gamma_{x} h \\
F_{z_{f}}+F_{z_{r}} & =M g
\end{aligned}\right.
$$

where the index $f$ and $r$ denote front and rear for vertical efforts $F_{z}$ and wheelbases $L, \gamma_{x}$ is the longitudinal acceleration, $M$ is the vehicle mass, and $h$ the nominal height of the center of gravity. The vertical effort estimators can then be easily obtained as follows

$$
\left\{\begin{array}{c}
F_{z_{f}}=\frac{M L_{r}}{2\left(L_{f}+L_{r}\right)}\left(g-h \frac{\hat{\gamma}_{x}}{L_{r}}\right) \\
F_{z_{r}}=\frac{M L_{f}}{2\left(L_{f}+L_{r}\right)}\left(g+h \frac{\hat{\gamma}_{x}}{L_{f}}\right)
\end{array}\right.
$$


Note that vehicle mass $M$, the height of the center of gravity $h$ and yaw inertia moment $I$-used in (6)- are not constant parameters, and therefore not easy to accurately measure. An off-line identification has been performed in order to know these values for the presented specific study cases. However, an on-line estimation of these two variable parameters should be done to robustify the algorithm. In this connection, asymptotic [23] or least squares [9] approaches could be excellent candidates to be adapted within the algebraic framework used in this paper.

Remark 3.1. Longitudinal acceleration is usually an available measurement in production cars. However, since sensors providing this signal are really lowcost, their measurements are especially noisy. Filtering techniques introduced in Section 2.1 are used to obtain a denoised $\gamma_{x}$ as follows:

$$
\hat{\gamma}_{x}=\int_{0}^{T}(2 T-3 t) \gamma_{x}(t) d t
$$

where $[0, T]$ is a quite short and sliding time window.

Figure 4 shows experimental results of the $F_{z}$ estimator, which, in general terms, performs pretty well.

Remark 3.2. All the experimental results presented in this section and in Section 6 comes from an extensive experimentation campaign with Peugeot 406, where only the driver was inside (1650 kg). In Fig 4 and 6, the vehicle was running at around $28.6 \mathrm{~ms}^{-1}$ on a dry surface $\left(\mu_{\max }=1.1\right)$, when the maximum allowed longitudinal deceleration is applied with a freewheel brake until the vehicle is stopped.

Using Newton's second law of motion, front and rear longitudinal efforts can be expressed as follows

$$
F_{x_{f}}=M_{e q_{f}} \gamma_{x}, M_{e q_{f}}=\frac{F_{z_{f}}}{g} ; F_{x_{r}}=M_{e q_{r}} \gamma_{x}, M_{e q_{r}}=\frac{F_{z_{r}}}{g}
$$



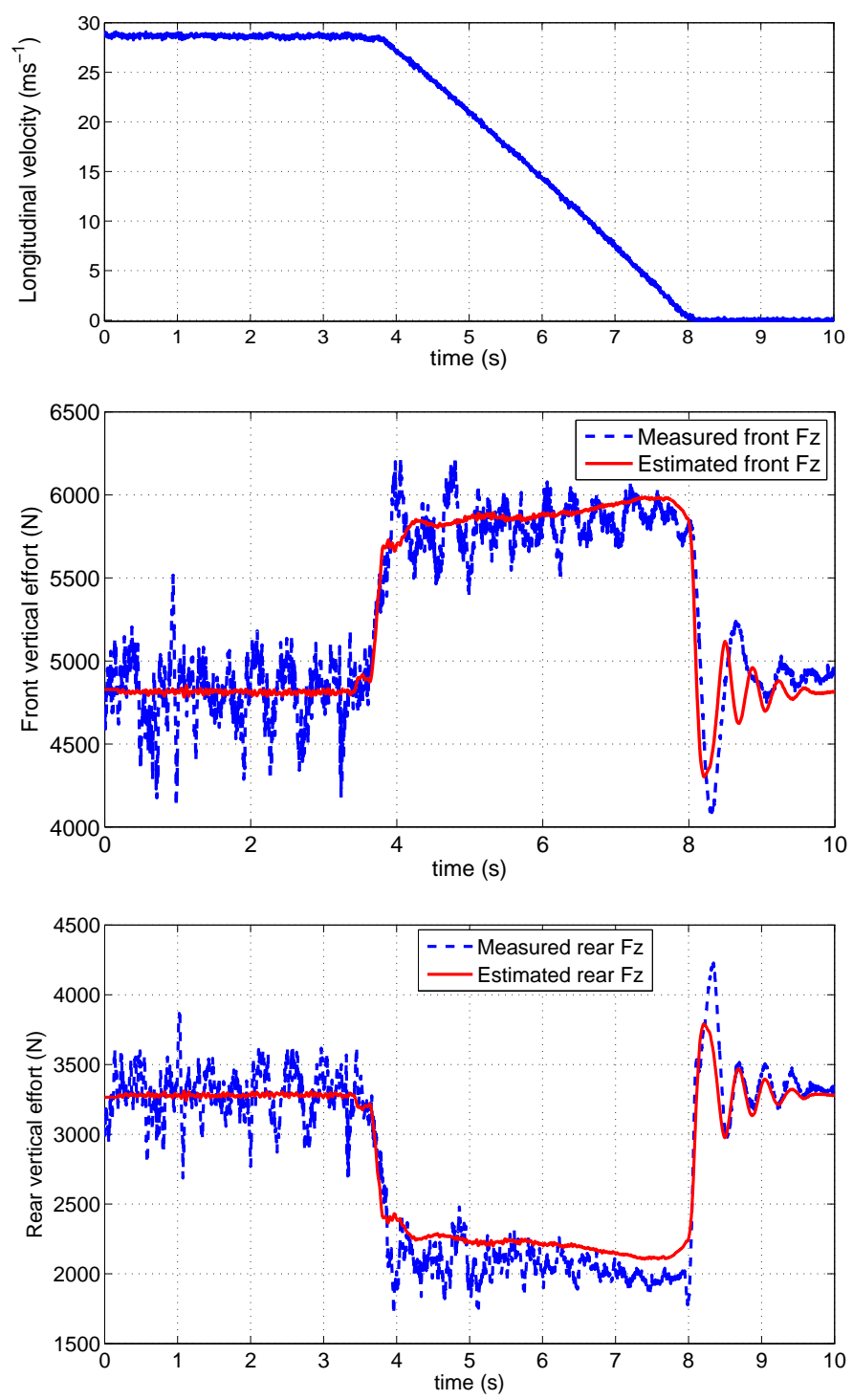

Figure 4: Front and rear tire normal forces estimation from experimental results. 
where $M_{e q_{(f, r)}}$ are the front and rear equivalent masses, respectively. Hence, the front and rear friction coefficients (1) turn out to be equal and on only dependent on the longitudinal acceleration $\gamma_{x}$

$$
\mu_{x_{f}}=\mu_{x_{r}}=\frac{F_{x_{f}}}{F_{z_{f}}}=\frac{F_{x_{r}}}{F_{z_{r}}}=\frac{\gamma_{x}}{g}
$$

Since this approach does take into account neither the vertical nor the pitch dynamics, an additional term will be introduced in order to achieve better estimations of $\mu_{x}$. Experimental measurements have shown that the addition of a corrective term $\Delta \mu_{x_{\phi}}$, proportional to the integral of pitch angle, remarkably corrects the estimation error obtained with (3):

$$
\mu_{x}=\frac{\gamma_{x}}{g}\left(1+\Delta \mu_{x_{\phi}}\right)
$$

Following the approach of [36], the kinematic relationship between the outputs of an inertial measurement unit and the derivatives of the Euler angles can be written, in its longitudinal component

$$
\dot{V}_{x}=\gamma_{x}+\dot{\psi} V_{y}-\dot{\phi} V_{z}+g \sin \phi
$$

with $V_{z}$ the vertical velocity. If the vertical velocity is neglected ${ }^{5}$ and the longitudinal velocity is considered equal to $r \omega$, the following pitch angle estimator $\hat{\phi}$ can be obtained from (5)

$$
\hat{\phi}=\arcsin \left(\frac{\gamma_{x}-\dot{\psi} V_{y}-r \dot{\omega}}{g}\right)
$$

\footnotetext{
${ }^{5}[36]$ justifies this simplification with very satisfying results of a pitch angle estimation proposed by the same authors.
} 
The corrective term $\Delta \mu_{x_{\phi}}$ of equation (4) is numerically computed with the next algorithm

$$
\left\{\begin{aligned}
\Delta \mu_{x_{\phi}}(t) & =\int_{T_{i_{\phi}}}^{T_{f_{\phi}}} K_{\phi} \hat{\phi}(t) d t, \text { if }|\hat{\phi}(t)|>\varepsilon_{1}, 0<\varepsilon_{1} \ll 1 \\
\Delta \mu_{x_{\phi}}(t) & =0, \text { else }
\end{aligned}\right.
$$

where $T_{i_{\phi}}$ and $T_{f_{\phi}}$ are respectively the initial and final time where the pitch variation is significative (i.e. $|\hat{\phi}(t)|$ is greater than a threshold $\varepsilon_{1}$ ), and $K_{\phi}$ is an off-line identified parameter ${ }^{6}$, which represents the normalized pitch stiffness.

Figure 5 shows the different behavior between (3) and (4) when demanding braking efforts are applied to the vehicle. These results have been obtained from experimental data recorded on a real vehicle with noisy measurements (see Section 6 for all details).

Notice $^{7}$ from Fig. 6 that Equation (4) also provides reasonably good longitudinal forces estimations when a combined longitudinal/lateral acceleration is applied to the vehicle. Noise robustness and delay quantification are essential for an estimation algorithm. As stated in Section 2.1, two different works have been recently published on this respect for the proposed numerical differentiators. These studies are a first step towards a deterministic quantification of the delay/filtering trade-off, always delicate for the designer.

Remark 3.3. When a $\mu$-split situation occurs, the previous assumptions are not fulfilled. Therefore, the proposed longitudinal friction estimator will provide some sort of average front and rear friction coefficient. A deeper study has to be done to

\footnotetext{
${ }^{6}$ An adaptation of roll stiffness estimation developed in [32] has been used in this work for pitch stiffness identification.

${ }^{7}$ So far these results have been verified only in simulation.
} 
guarantee a functional estimator for this kind of extreme situations. To separately estimate friction on each front or rear wheel, yaw and roll dynamics should be considered.

Remark 3.4. The previous pitch estimator has been designed following the methodology introduced in Section 2.1, i.e. robust algebraic techniques for filtering and estimation are combined within a classical fault diagnosis framework to obtain the desired estimates.

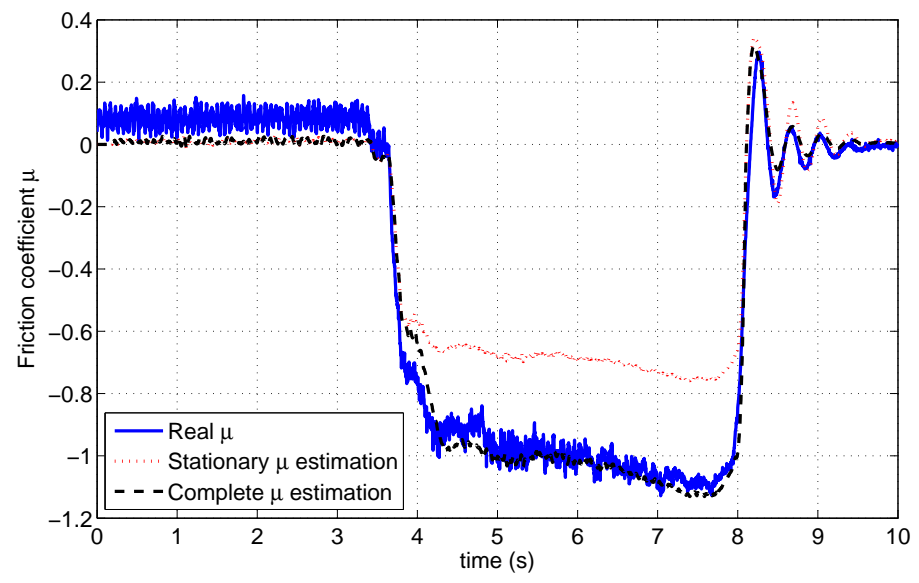

Figure 5: Longitudinal friction estimation comparison between equations (3) and (4) from real data measurements.

\subsection{Lateral effort estimation}

The single $\operatorname{track}^{8}$ (or bicycle) model is the most spread one to study lateral dynamics in a car. The state vector is only conformed by lateral velocity and yaw rate, while longitudinal velocity is considered a slowly variable parameter of the

\footnotetext{
${ }^{8}$ See [20] or [15] for a deep analysis on this and other vehicle models.
} 

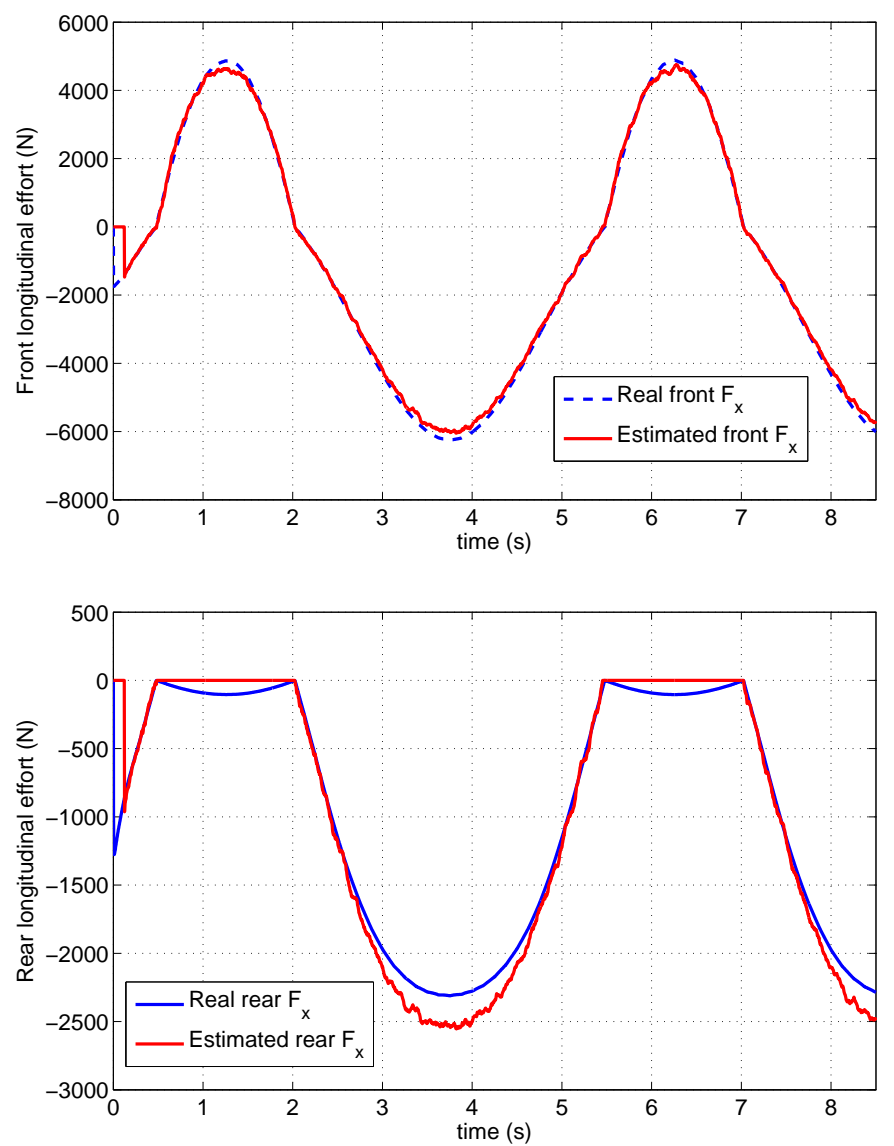

Figure 6: Comparison between real and estimated longitudinal efforts in a mixed braking and turning maneuver: front $F_{x}$ (left) and rear $F_{x}$ (right) 
resultant linear system. Since state variables estimation is not the main goal, but rather lateral forces estimation, the bicycle model will be written in terms of the latter using Newton's second law of motion:

$$
\left\{\begin{aligned}
M \gamma_{y} & =F_{y_{f}}+F_{y_{r}} \\
I \ddot{\psi} & =L_{f} F_{y_{f}}-L_{r} F_{y_{r}}
\end{aligned}\right.
$$

where $M$ is the vehicle mass, $I$ the yaw inertia moment, $L_{f}, L_{r}$ are the front and rear wheelbases, and $F_{y_{f}}, F_{y_{r}}$ the front and rear lateral forces, respectively.

The choice of such a model is not at all arbitrary. Indeed, it represents a very interesting trade-off between simplicity and accuracy. In this connection, several works claim the interest (see, e.g., [3]) of the bicycle model to estimate lateral efforts, even under important longitudinal accelerations.

Equation (6) can be rewritten in terms of $F_{y_{f}}$ and $F_{y_{r}}$

$$
\left\{\begin{array}{c}
\hat{F}_{y_{f}}=\frac{1}{L_{f}+L_{r}}\left(L_{f} M \hat{\gamma}_{y}-I \hat{\ddot{\psi}}\right) \\
\hat{F}_{y_{r}}=\frac{1}{L_{f}+L_{r}}\left(L_{r} M \hat{\gamma}_{y}-I \hat{\ddot{\psi}}\right)
\end{array}\right.
$$

Figure 7 shows the estimator performance in a severe longitudinal/lateral maneuver. It shows, on the one hand, the quality of the lateral forces estimation for very noisy measurements, and on the other hand, that the single-track model may be enough to properly estimate $F_{y}$ under combined efforts.

\section{From instantaneous friction to maximum friction estimation}

The last stage in the global estimation scheme (presented in Figure 2) is probably the most complicated one. This complexity comes from the fact that most of the road surfaces (from ice to dry asphalt) have a very similar characteristic curve $\left(\mu_{x}-\tau\right)$ for standard situations. However, when difficult situations arise, 

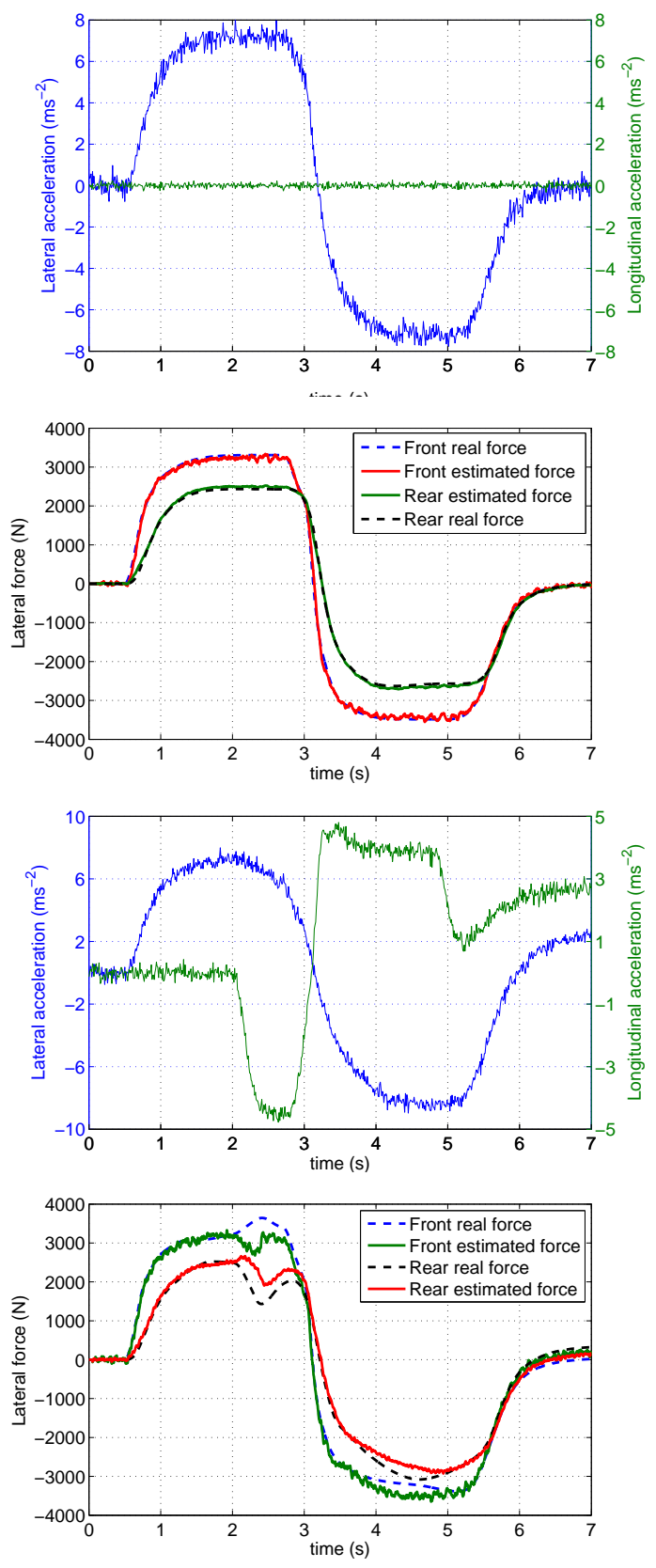

Figure 7: Lateral tire forces estimation: a) Pure lateral maneuver at $15 \mathrm{~ms}^{-1}$, longitudinal and lateral accelerations; b) Front and rear lateral effort estimation; (c) Combined longitudinal-lateral maneuver at $15 \mathrm{~ms}^{-1}$; d) Front and rear lateral effort estimation 
i.e. when the $\mu_{x}-\tau$ curve clearly discriminates a surface from another, the information about the tire-road interface might arrive too late.

In other words, while the vehicle is in the linear $\left(\mu_{x}-\tau\right)$ zone, there is a strong risk of indistinguishability (see [12]) of the type of surface, and therefore, to fail in predicting the maximum friction coefficient. ${ }^{9}$

Hence, this approach tends to take advantage of the presented numerical algorithms to be able to detect danger zones in a reliable way. Once the 'failure' is detected, a simple tire behavior model (section 4.1) will help to obtain a good estimation of $\mu_{x_{\max }}$ slightly ahead of time.

\subsection{Dugoff model}

Since the physics of tire force generation is highly nonlinear and complex, several tire models have been introduced to overcome this problem (see [34] and the references therein). The pseudo-static model from [29] gives a good approximation to experimental results and is widely used in automotive research and industries. However, this model has a complex analytical structure and its parameters are difficult to identify. For these reasons, it is mainly used for simulation rather than for control or estimation purposes.

Dugoff tire model [7] assumes a uniform vertical pressure distribution on the tire contact patch. This is a simplification compared to the more realistic parabolic pressure distribution assumed in Pacejka. However, it has the advantage of its conciseness and its results are considered to be on the safe side in an emergency situation. Furthermore, the lateral and longitudinal forces are directly related to

\footnotetext{
${ }^{9}$ Some authors, like for instance [17], have tried to classify the road friction only with the wheel's rotation dynamics, but their results are not conclusive.
} 
the maximum friction coefficient in more transparent equations than in Pacejka model.

Dugoff model accuracy will then be evaluated as a good candidate to estimate $\mu_{x_{\max }}$. Longitudinal efforts are modeled as follows

$$
F_{x}=f(\lambda) K_{x} \tau
$$

where $\tau$ is the slip ratio, $K_{x}$ is the longitudinal stiffness coefficient and $f(\lambda)$ is a piecewise function

$$
f(\lambda)=\left\{\begin{array}{cc}
(2-\lambda) \lambda & , \lambda<1 \\
1 & , \lambda \geqslant 1
\end{array}, \lambda=\frac{\mu_{x_{\max }} F_{z}}{2\left|K_{x} \tau\right|}\right.
$$

It is not difficult to see that $\mu_{x_{\max }}$ can be expressed in terms of 4 a priori known variables ${ }^{10} \mu_{x_{\max }}=g\left(F_{x}, F_{z}, \sigma, K_{x}\right)$. Let us take the nonlinear zone case, i.e. $f(\lambda)=(2-\lambda) \lambda$

$$
F_{x}=\left(\frac{2-\mu_{x_{\max }} F_{z}}{\left|K_{x} \tau\right|}\right) \frac{\mu_{x_{\max }} F_{z}}{\left|K_{x} \tau\right|} K_{x} \tau
$$

This expression can be rewritten as a second order algebraic equation of the maximum friction coefficient:

$$
\mu_{x_{\max }}^{2} F_{z}^{2}-2 \mu_{x_{\max }}\left|K_{x} \tau\right| F_{z}+\left|K_{x} \tau\right| F_{x}=0
$$

whose two solutions

\footnotetext{
${ }^{10}$ While $F_{x}, F_{z}$ and $\tau$ are byproducts of the proposed global estimation scheme, a nominal $K_{x}$ could be obtained either by an off-line or an online identification, following techniques introduced in Section 2.1.
} 


$$
\mu_{x_{\max }}=\frac{\left(\left|K_{x} \tau\right| \pm \sqrt{K_{x} \tau\left(K_{x} \tau-F_{x}\right)}\right)}{F_{z}}
$$

are always real because $K_{x} \tau(t)-F_{x}(t) \geqslant 0, \forall t$.

Figure 8 shows a longitudinal force comparison between Pacejka and Dugoff models. A similar behavior can be appreciated for 3 different maximum friction coefficients $\left(\mu_{x_{\max }}=0.4, \mu_{x_{\max }}=0.7\right.$ and $\left.\mu_{x_{\max }}=1\right)$ :

- While Pacejka curves reach a maximum effort point and thereafter always decay (uncontrolled vehicle zone), Dugoff model has a monotone behavior, i.e. the $F_{x}$ peak never appears.

- For a same longitudinal stiffness coefficient $K_{x}$, the trends in both models are quite similar in the linear zone, but they saturate at different levels. A third curve has been introduced in all figures to weight Dugoff model so that its maximum forces are comparable to Pacejka model.

- Exhaustively comparing Pacejka and Dugoff models by means of simulations, it has been found that the weighting factor $\alpha$ previously mentioned is the same for any $\mu_{x_{\max }}$ and drive Dugoff model to cross through Pacejka model exactly in the $F_{x}$ peak.

As a result of the previous statements, $\mu_{x_{\max }}$ prediction model will be obtained by weighting the minimum value of (7):

$$
\begin{aligned}
\hat{\mu}_{x_{\text {max }}}^{D}\left(t_{k}\right) & =\frac{\alpha}{\hat{F}_{z}(t)}\left(\left|K_{x} \hat{\tau}\left(t_{k}\right)\right|\right. \\
& \left.-\sqrt{K_{x} \hat{\tau}\left(t_{k}\right)\left(K_{x} \hat{\tau}\left(t_{k}\right)-\hat{F}_{x}\left(t_{k}\right)\right)}\right), \lambda\left(t_{k}\right)<1 \\
\hat{\mu}_{x_{\text {max }}}^{D}\left(t_{k}\right) & =\hat{\mu}_{x_{\text {max }}}^{D}\left(t_{k-1}\right), \lambda\left(t_{k}\right) \geqslant 1
\end{aligned}
$$



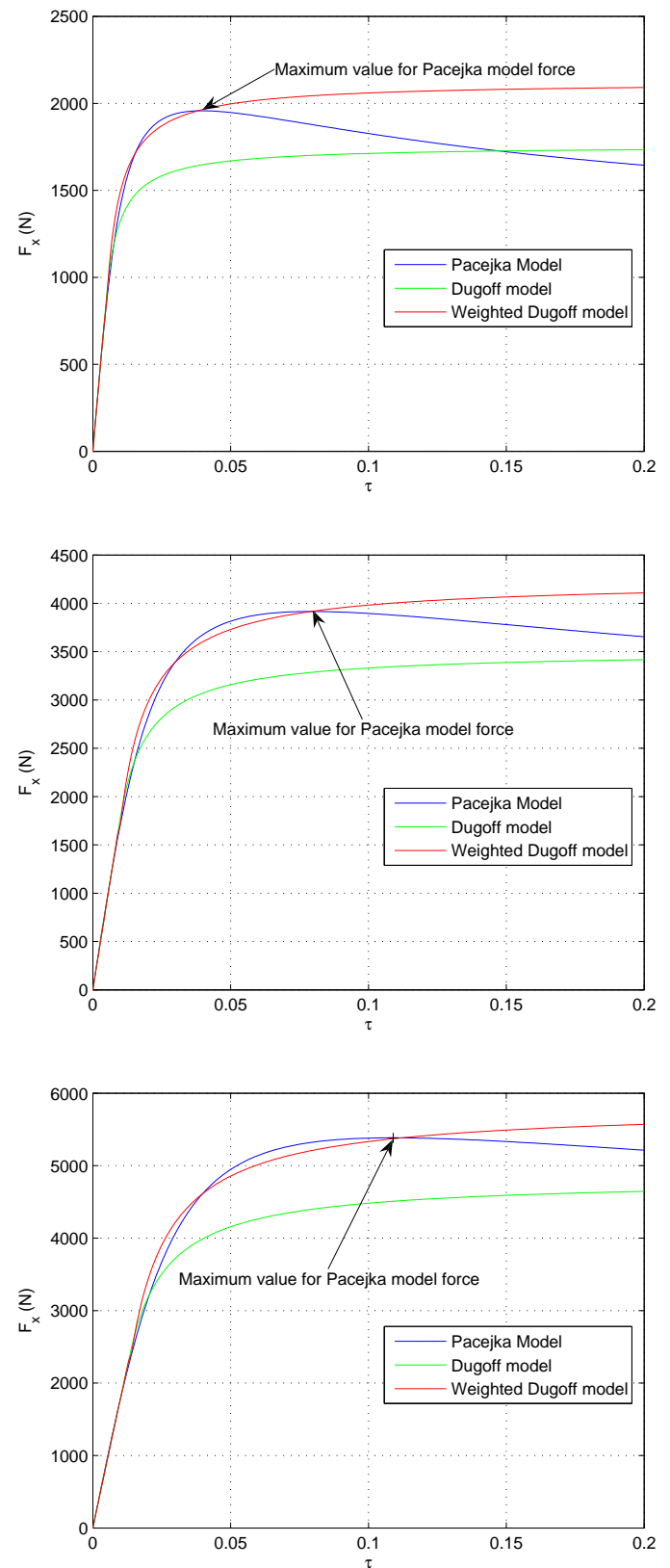

Figure 8: Comparison between Pacejka, Dugoff and modified Dugoff tire models for 3 different roads with the same wheel load $\left(F_{z}=4500 N\right)$. (a) $\mu_{x_{\max }}=0.4$, (b) $\mu_{x_{\max }}=0.7$ and (c) $\mu_{x_{\max }}=1$. 


\subsection{Detection algorithm}

As stated in the introduction, the extended braking stiffness (XBS) will be used to detect the entrance in danger zone (or, in other words, to signal the distinguishability between road surfaces).

XBS was defined by [28] as the derivative of the friction coefficient with respect to slip ratio. Therefore, the switching function will be given by the following XBS estimator:

$$
X B S(t)=\frac{d \mu_{x}}{d \tau}=\frac{d \mu_{x}}{d t} \frac{d t}{d \tau}=\frac{\hat{\dot{\mu}}_{x}}{\hat{\hat{\tau}}}
$$

where $\hat{\dot{\mu}}_{x}$ and $\hat{\dot{\tau}}$ are obtained using algebraic algorithms [26].

The main difficulty in this computation is to obtain numerical derivative estimators such that a good trade-off between filtering and reactivity is achieved.

Algebraic derivative estimators are compared for a particular scenario to the analytical derivatives in Figures 9a and 9c. Both derivative estimators perform in a satisfactory way, even with singular behaviors such as sudden changes of $\mu_{x_{\max }}$ (i.e. at $\mathrm{t}=3 \mathrm{~s}$ ). The analytical values present a hard discontinuity at that point, but it is pretty well filtered by the proposed estimators.

Also in Figure 9 (b and d) a comparison between filtered XBS and $\mu_{x}$ evolution is shown. Similar trends can be appreciated in both graphs, i.e. when $\mu_{x}$ reaches a local peak, XBS is close to local minima. Furthermore, the closest $\mu_{x}$ is to $\mu_{x_{\max }}$, the lower value of XBS is obtained. As a result of this, an XBS validity range ( $\left[X B S_{\max }, X B S_{\min }\right]$ can be selected as significative for $\mu_{x_{\max }}$ detection. Thus, when XBS values are greater than $X B S_{\max }$ or lower than $X B S_{\min }$, it will be considered that $\mu_{x}$ remains equal to the last obtained value within the validity range. If $\mu_{x}$ falls into the validity range, a corrective factor will be applied to the $\mu_{x_{\max }}(t)$ predicted value by equation (8). Finally, a $[0,1.2]$ saturation function is used to correct the 
previous value in case the estimation exceeds realistic friction limits. To sum up, the final algorithm can be concisely written as follows:

$$
\begin{aligned}
& \text { if } X B S\left(t_{k}\right) \leqslant X B S_{\max } \\
& \mu_{x_{\max }}\left(t_{k}\right)=\max \left(0, \min \left(1.2, \mu_{x_{\max }}^{*}\left(t_{k}\right)\right)\right) \\
& \mu_{x_{\max }}^{*}\left(t_{k}\right)=\mu_{x_{\max }}^{D}\left(t_{k}\right)\left(1+\chi \frac{X B S\left(t_{k}\right)}{X B S_{\max }}\right) \\
& \text { if } X B S_{\max } \leqslant X B S\left(t_{k}\right) \\
& \mu_{x_{\max }}\left(t_{k}\right)=\mu_{x_{\max }}\left(t_{k-1}\right)
\end{aligned}
$$

Remark 4.1. Parameter $\chi$ acts as a confidence factor of the friction value provided by Dugoff model within the validity range. It can be seen from equation (9) that the nearest $X B S$ is to $X B S_{\max }$, the closest the factor $\frac{X B S\left(t_{k}\right)}{X B S_{\max }}$ is from 1 . On the contrary, when XBS tends to 0 , the same stands for $\frac{X B S\left(t_{k}\right)}{X B S_{\max }}$. The value of parameter $\chi$ is always close to 1 and its optimum value depends on the measurement noise nature.

Remark 4.2. The same procedure presented here will be used to estimate lateral maximum friction coefficient from its instantaneous value, which in turn, will be computed from pre-estimated vertical loads $\hat{F}_{z}$ and lateral efforts $\hat{F}_{y}$.

\section{Simulation results of friction estimation}



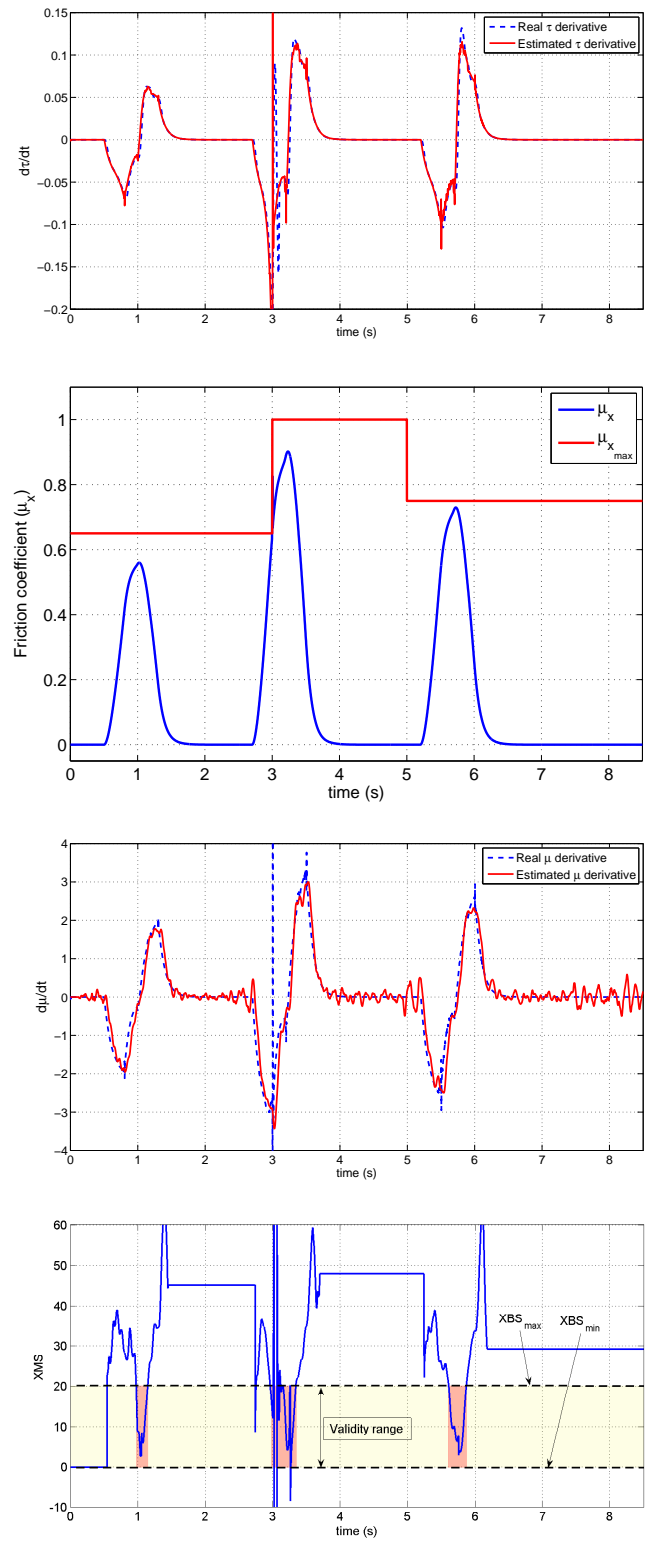

Figure 9: eXtended Braking Stiffness estimation. a)Comparison between $\tau$ algebraic derivative estimation and its analytical value. b)Real $\mu_{x}$ and $\mu_{x_{\max }}$ evolution. c)Comparison between $\mu_{x}$ algebraic derivative estimation and its analytical value. d)XBS estimation, validity range and $\mu_{x_{\max }}$ distinguishable zones. 

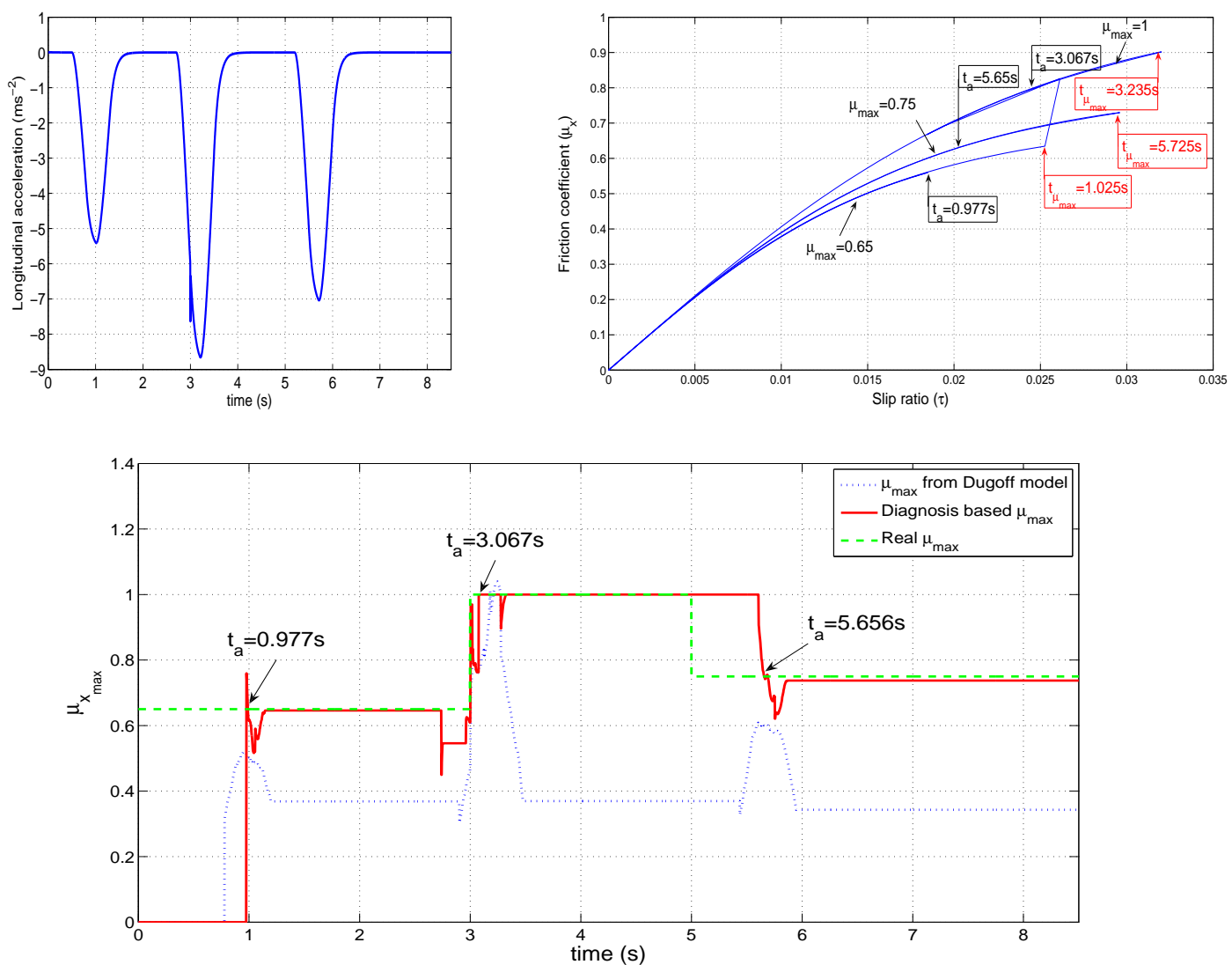

Figure 10: First scenario: a) Longitudinal acceleration b) $\mu_{x}-\tau$ graph with maximum friction and detection instants c) Maximum adherence estimation during the first multi-adherence scenario

Two different scenarios have been used to test the algorithm in a simulation environment ${ }^{11}$. In both of them, each of the 3 braking phases is carried out under different friction conditions. Thus, while in the first case $\mu_{x_{\max }}(t)=$ $0.65, t \in[0,3], \mu_{x_{\max }}(t)=1, t \in[3,5], \mu_{x_{\max }}(t)=0.75, t \in[5,8.5]$, in the second one $\mu_{x_{\max }}(t)=1, t \in[0,3], \mu_{x_{\max }}(t)=0.35, t \in[3,5], \mu_{x_{\max }}(t)=0.7, t \in[5,8.5]$.

\footnotetext{
${ }^{11} \mathrm{~A}$ realistic simulator of a vehicle with 14 degrees of freedom, and with complete suspension and tire models (see [29]) has been used in all simulations.
} 

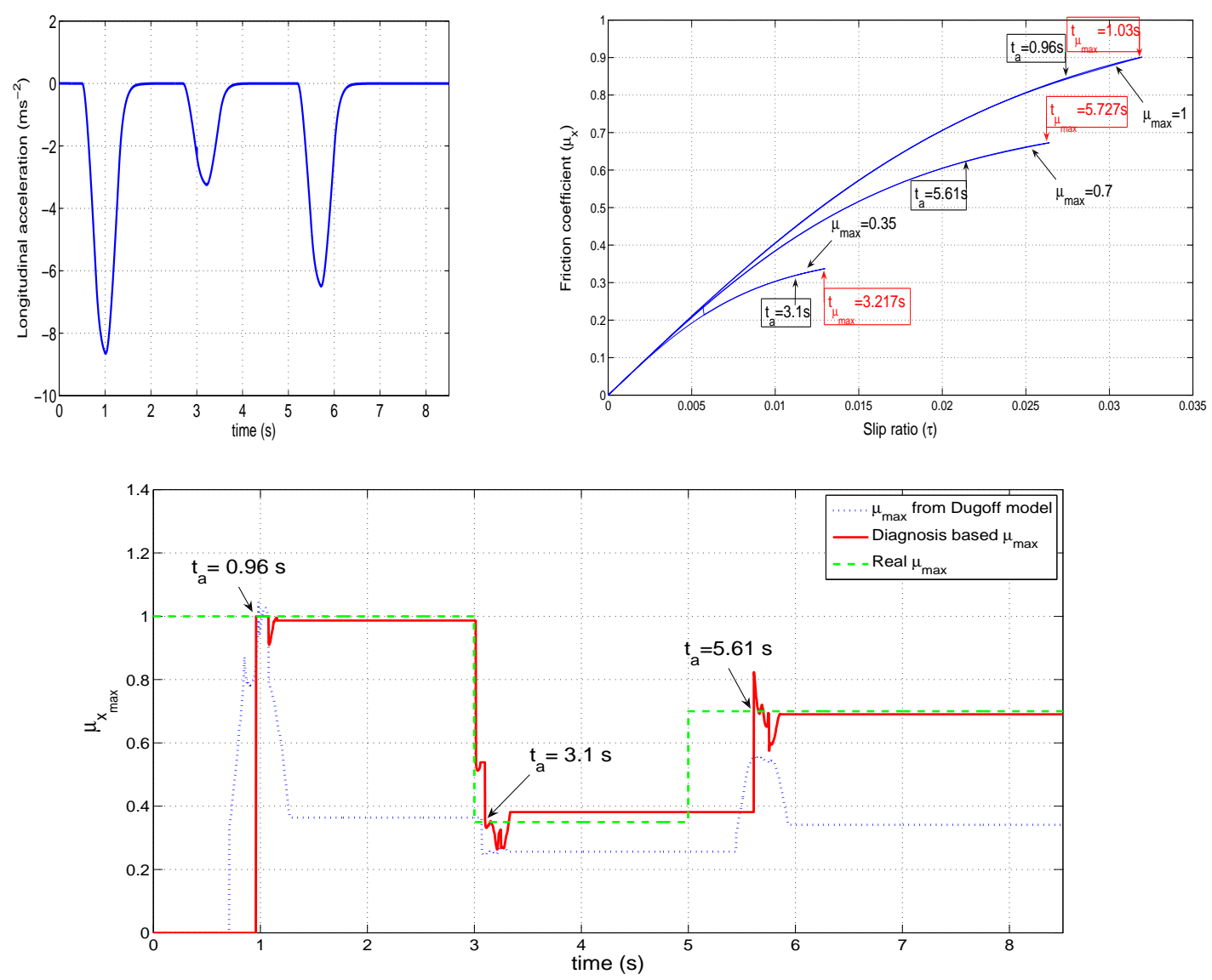

Figure 11: Second scenario: a)Longitudinal acceleration b) $\mu_{x}-\tau$ graph with maximum friction and detection instants c)Maximum adherence estimation during the first multi-adherence scenario

The applied braking efforts have been chosen to be useful for the proposed failure detection algorithm, i.e. strongly enough to leave the linear zone, but softly enough to avoid tire saturation.

Figure 10 shows the simulation results for the first scenario. A vehicle begins to move at $15 \mathrm{~ms}^{-1}$ and 3 braking actions are consecutively applied so that the resulting longitudinal accelerations are those of Figure 10a). The bottom graph of 
the same figure plots the friction coefficient and its estimation, with the instants $t_{\mu_{\max }}$ where minimum values are attained. This information can be complemented with Figure $10 \mathrm{~b}$, where $\mu_{x}-\tau$ evolution can be very well distinguished for all 3 tire-road interfaces. Moreover, alarm times $\left(t_{a}\right.$, in black), coming from the estimation algorithm, always arise sufficiently in advance with respect to maximum friction instants $t_{\mu_{\max }}$ (in red).

Bottom graph of Figure 10 compares the real $\mu_{x_{\max }}$ obtained values, on the one hand, with Dugoff prediction model, and on the other hand, with the weighted Dugoff prediction model ${ }^{12}$. Besides the fact the alarm times seem to be sufficiently ahead of time, the estimation error is significantly small.

These promising results are confirmed in a second multi-adherence scenario (Fig.11). Remark that in both maneuvers, only when important braking actions are carried out, the estimator algorithm change its value (cf. i.e. in the second scenario, between $t=5 \mathrm{~s}$ and $t_{a}=5.61$, the estimated $\mu_{x_{\max }}$ is not updated because there is a problem of distinguishability).

\section{Experimental results of friction estimation}

Several braking maneuvers have been realized on roads with different maximum friction coefficient. In every test, a large set of dynamic variables has been recorded at high frequency rates (around $250 \mathrm{~Hz}$ ) on an instrumented vehicle.

The promising results obtained in simulation have been confirmed with real data in severe braking maneuvers. Two examples of this satisfactory results are plotted in Figures 12 and 13.

\footnotetext{
${ }^{12}$ As aforementioned, $\mu_{x_{\max }}$ estimation is updated when XBS is within its validity range.
} 


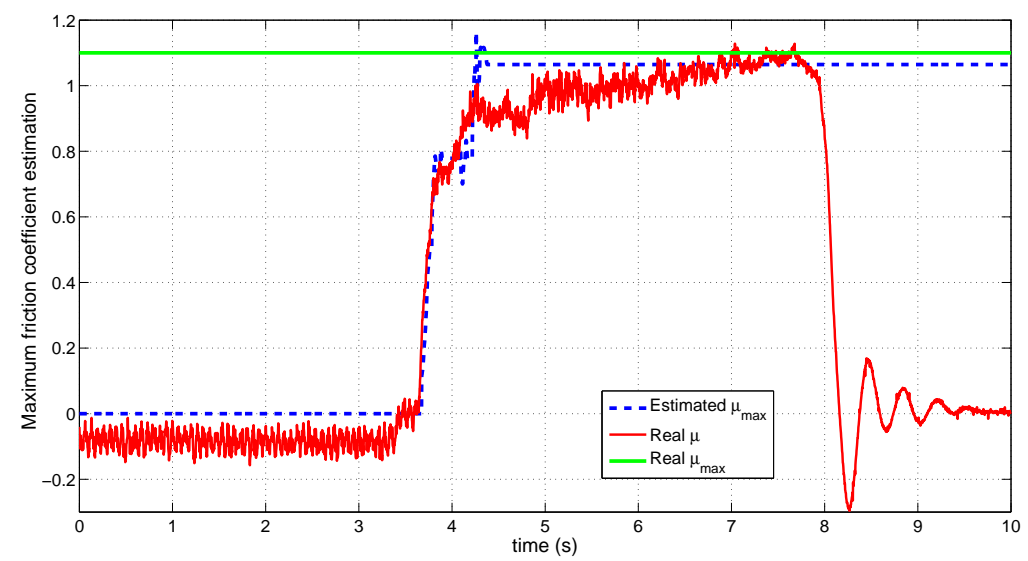

Figure 12: Maximum friction estimation for the first experimental maneuver.

In the first case, the vehicle is moving at a constant speed $\left(100 \mathrm{kmh}^{-1}\right)$ on a dry road $\left(\mu_{x_{\max }}=1.1\right)$, when a sudden and hard braking effort is applied at $t=3.5 \mathrm{~s}$. The vehicle remains braking close to the maximum tire-road friction coefficient until it stops at $t=8.5 \mathrm{~s}$. The real friction coefficient $\mu_{x}$ increases rapidly around $t=3.5 \mathrm{~s}$, but it does not attain its maximum value almost until the end of the braking maneuver. This monotone behavior, probably due to the the fact that wheels do not get blocked, is not an obstacle to the estimator, which obtains a constant value of $\hat{\mu}_{x_{\max }}=1.07$ at $t=4.2 \mathrm{~s}$, sufficiently in advance of the $\mu_{x}$ peak.

The second case is again a vehicle moving at a constant speed $\left(60 \mathrm{kmh}^{-1}\right)$ in a straight line on a wet road $\left(\mu_{x_{\max }}=0.8\right)$. As it can be appreciated in Fig. 13, the results are even more satisfactory than in the previous case. On the one hand, the estimated value is now even closer to the real value, and on the other hand, the transient state is much shorter than before. 


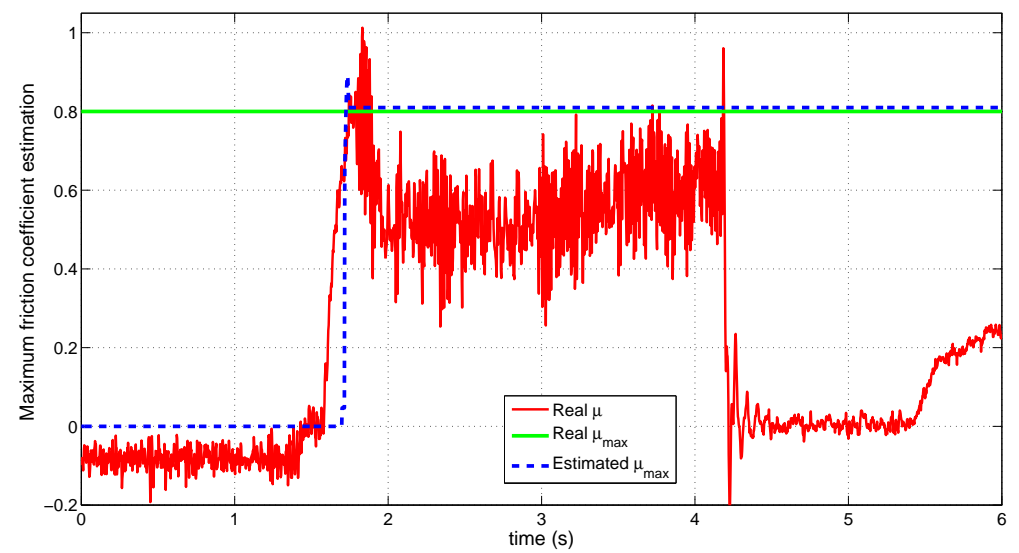

Figure 13: Maximum friction estimation for the second experimental maneuver.

\section{Conclusion and future work}

A new approach to estimate vehicle tire forces and road maximum adherence is presented in this paper. It is based on the combination of elementary diagnosis tools and new algebraic techniques for filtering and estimating derivatives. First of all, instantaneous friction and lateral forces are estimated. Then, extended braking stiffness concept is exploited to detect which braking efforts allows to distinguish a road type from another. Very promising results have been obtained in noisy simulations and in real experimentations.

However, the validity domain of this novel global estimation scheme remains still limited. Therefore, more exhaustive tests with real data will have to be performed in difficult situations like mu-split or emergency braking while turning. In this connection, a deep sensitivity analysis to vehicle parameters and noise measurements will be performed.

Future work will also have to be done to characterize the robustness of parameter $\chi$ with respect to the measurement noises. When this task will be completed, 
a real friction-dependent stop-and-go control strategy (see [38] or [39]) will be implemented to validate the preliminary results presented here.

Let us emphasize finally that the practical usefulness in the automotive industry of these new algebraic techniques is confirmed by other successful applications $[1,2,19,38,39,40]$.

\section{Acknowledgement}

The authors wish to thank the anonymous reviewers for their most valuable comments which helped them to greatly improve their paper.

\section{References}

[1] H. Abouaissa, M. Fliess and C. Join, 'Fast parametric estimation for macroscopic traffic flow model,' Proc. 17th IFAC World Congress, Seoul, 2008 (available at http://hal.inria.fr/inria-00259032/en/).

[2] B. d'Andréa-Novel, C. Boussard, M. Fliess, O. el Hamzaoui, H. Mounier and B. Steux, 'Commande sans modèle de vitesse longitudinale d'un véhicule électrique,' Actes $6^{e}$ Conf. Internat. Francoph. Automat., Nancy, 2010 (available at http://hal.inria.fr/inria-00463865/en/).

[3] G. Baffet, A. Charara, D. Lechner, 'Estimation of vehicle sideslip, tire force and wheel cornering stiffness,' Control Engineering Practice, vol. 17, pp. 1255-1264, 2009.

[4] B. Breuer, U. Eichhorn and J. Roth, 'Measurement of tyre/road friction ahead of the car and inside the tyre,' Proc. AVEC92, pp. 347-352, London, UK, 1992. 
[5] C. Canudas-de-Wit, P. Tsiotras, E. Velenis, M. Basset and G. Gissinger 'Dynamic friction models for road/tire longitudinal interaction,' Vehicle System Dynamics, vol. 39, pp. 189-226, 2002.

[6] J. Dakhlallah, S. Glaser, S. Mammar and Y. Sebsadji, 'Tire-road forces estimation using extended Kalman filter and sideslip angle evaluation,' Proc. Amer. Control Conf., pp. 4597-4602, Seattle, 2008.

[7] H. Dugoff, P. S. Fancher, and L. Segel, 'Tire performance characteristics affecting vehicle response to steering and braking control inputs,' Technical Report, Highway Safety Research Institute, Ann Arbor, MI, 1969.

[8] U. Eichhorn and J. Roth, 'Prediction and monitoring of tyre/road friction' Proc. of FISITA 24th Congress: Safety, the Vehicle, and the Road, pp. 67-74, London, UK, 1992.

[9] H.K. Fathy, D. Kang and J.L. Stein, 'Online vehicle mass estimation using recursive least squares and supervisory data extraction,' Proc. Amer. Control Conf., Seattle, WA, 2008.

[10] D. Fischer, M. Börner, J. Schmitt and R. Isermann, 'Fault detection for lateral and vertical vehicle dynamics,' Control Engineering Practice, vol 15, pp. 315-324, 2009.

[11] M. Fliess and C. Join, 'Commande sans modèle et commande à modèle restreint,' e-STA, vol. 5 ( $\mathrm{n}^{0}$ 4), pp. 1-23, 2008 (available at http://hal.inria.fr/inria-00288107/en/).

[12] M. Fliess, C. Join and W. Perruquetti, 'Real-time estimation for switched 
linear systems,' Proc. 47 $7^{\text {th }}$ IEEE Conf. Decision Control, pp. 941-946, Cancun, 2008.

[13] M. Fliess, C. Join, and H. Sira-Ramírez, 'Non-linear estimation is easy,' Int. J. Modelling Identification Control, Vol. 4, pp. 12-27, 2008 (available at http://hal.inria.fr/inria-00158855/en/).

[14] F.A. García Collado, B. d'Andréa-Novel, M. Fliess and H. Mounier, 'Analyse fréquentielle des dérivateurs algébriques,' XXII Coll. GRETSI, Dijon, 2009 (available at http://hal.inria.fr/inria-00394972/en/).

[15] T.D. Gillespie, 'Fundamentals of vehicle dynamics', Society of Automotive Engineers, 1992.

[16] H.F. Grip, L. Imsland, T.A. Johansen, T.I. Fossen, H.F. Grip,c, J. C. Kalkkuhl and A. Suissa, 'Nonlinear vehicle side-slip estimation with friction adaptation,' Automativa, vol. 44, pp. 611-622, 2008.

[17] F. Gustafsson, 'Slip-based estimation of tire-road friction,' Automatica, vol. 33, pp. 1089-1099, 1997.

[18] J.O. Hahn, R. Rajamani and L. Alexander, 'GPS-Based real-time identification of tire-road friction coefficient,' IEEE Trans. Control Systems Technology, vol. 10, pp.331-343, 2002.

[19] C. Join, J. Masse, M. Fliess, 'Étude préliminaire d'une commande sans modèle pour papillon de moteur,' J. europ. syst. automat., vol. 42, pp. 337-354, 2008 (available at http: //hal.inria.fr/inria-00187327/en/). 
[20] U. Kiencke and A. Daib, 'Estimation of tyre friction for enhanced ABSsystem,' JSAE Review, vol. 10, pp. 221-226, 1995.

[21] U. Kiencke and L. Nielsen, 'Automotive control systems,' Springer, 2005.

[22] C. Lee, K. Hedrick and K. Yi, 'Real-time slip-based estimation of maximum tire-road friction coefficient,' IEEE/ASME Trans. Mechatronics, vol. 9, pp. 454-458, 2004.

[23] P. Lingman and B. Schmidtbauer, 'Road slope and vehicle mass estimation using Kalman filtering,' Vehicle System Dynamics, vol. 37, pp. 12-23, 2002.

[24] C.S. Liu and H. Peng, 'Road friction coefficient estimation for vehicle path prediction,' Vehicle System Dynamics, vol. 25, pp. 413-425, 1996.

[25] J. Matusko, I. Petrovic and N. Peric, 'Neural network based tire/road friction force estimation,' Engineering Appl. Artif. Intelligence, vol. 21, pp. 442-456, 2008.

[26] M. Mboup, C. Join and M. Fliess, 'Numerical differentiation with annihilators in noisy environment,' Numerical Algor., vol. 4, pp. 439-467, 2009.

[27] N.K. M'Sirdi, A. Rahbi, N. Zbiri, Y. Delanne, 'Vehicle-road interaction modelling for estimation of contact forces,' Vehicle System Dynamics, vol. 43, pp. 403-411, 2005.

[28] E. Ono, K. Asano, M. Sugai, S. Ito, M. Yamamoto, M. Sawada and Y. Yasui, 'Estimation of automotive tire force characteristics using wheel velocity,' Control Engineering Practice, vol. 11, pp. 1361-1370, 2003. 
[29] H. Pacejka and E. Baker, 'The magic formula tyre model,' Proc. ${ }^{\text {st }}$ Internat. Coll. Tyre Models Vehicle System Analysis, pp. 1-18, 1991.

[30] W.R. Pasterkamp and H.B. Pacejka, 'On line estimation of tyre characteristics for vehicle control,' JSAE Review, vol. 16, pp. 221-226, 1995.

[31] L. Ray, 'Nonlinear tire force estimation and road friction identification: simulation and experiments,' Automatica, vol. 33, pp. 1819-1833, 1997.

[32] J. Ryu, E.J. Rossetter and J.C. Gerdes, 'Vehicle sideslip and roll parameter estimation using GPS,' Proc. Internat. Symp. Advanced Vehicle Control (AVEC), Hiroshima, pp. 373-380, 2002.

[33] T. Shim and D. Margolis, 'Model-based road friction estimation,' Vehicle System Dynamics, vol. 41, pp. 241-276, 2004.

[34] J. Svendenius, 'Tire modeling and friction estimation', PhD Thesis, Dept. Automatic Control, Lund University, 2007.

[35] M. Tanelli, L. Piroddi and S.M. Savaresi, 'Real-time identification of tireroad friction conditions,' IET Control Theory Appl., vol. 3, pp. 891-906, 2009.

[36] H.E. Tseng, L. Xu and D. Hrovat, 'Estimation of land vehicle roll and pitch angles', Vehicle System Dynamics, vol. 45, pp. 433-443, 2007.

[37] T.Umeno, 'Estimation of tire-road friction by tire-rotational vibration model,' R\&D Review Toyota CRDL, vol. 37, pp. 53-58, 2002.

[38] J. Villagra, B. d'Andréa-Novel, S. Choi, M. Fliess and H. Mounier, 'Robust stop-and-go control strategy: an algebraic approach for nonlinear estimation 
and control,' Int. J. Vehicle Autonomous Systems, vol. 7, pp. 270-291, 2009 (available at http://hal.inria.fr/inria-00419445/en/).

[39] J. Villagra, B. d'Andréa-Novel, M. Fliess and H. Mounier, 'Robust grey-box closed-loop stop-and-go control,' Proc. $47^{\text {th }}$ IEEE Conf. Decision Control, pp. 5378-5383, Cancun, 2008 (available at http://hal.inria.fr/inria-00319591/en/).

[40] J. Villagra, B. d'Andréa-Novel, M. Fliess and H. Mounier, 'Estimation of longitudinal and lateral vehicle velocities: an algebraic approach,' Proc. Amer. Control Conf., pp. 3941-3946, Seattle, 2008 (available at http://hal.inria.fr/inria-00263844/en/)

[41] J. Villagra, B. d'Andréa-Novel, M. Fliess and H. Mounier, 'An algebraic approach for maximum friction estimation,' Proc. $8^{\text {th }}$ IFAC Symp. Nonlinear Control Systems (NOLCOS), Bologna, 2010 (available at http://hal.inria.fr/inria-00484781/en/).

[42] K. Yi, K. Hedrick and S.-C. Lee, 'Estimation of tire-road friction using observer based identifiers,' Vehicle System Dynamics, vol. 31, pp. 233-261, 1999.

[43] J. YI , L. Alvarez, X. Claeys and R. Horowitz, 'Emergency braking control with an observer-based dynamic tire/road friction model and wheel angular velocity measurement,' Vehicle System Dynamics, vol. 39, pp. 8197, 2003. 